\title{
Bioinformatics and evolutionary insight on the spike glycoprotein gene of QX-like and Massachusetts strains of infectious bronchitis virus
}

\author{
Shahid Hussain Abro ${ }^{1,2^{*}}$, Karin Ullman², Sándor Belák ${ }^{1,2}$ and Claudia Baule ${ }^{2}$
}

\begin{abstract}
Background: Infectious bronchitis virus (IBV) is a Gammacoronavirus of the family Coronaviridae and is a causative agent of an economically important disease in poultry. The spike glycoprotein of IBV is essential for host cell attachment, neutralization, and is involved in the induction of protective immunity. Previously obtained sequence data of the spike gene of IBV QX-like and Massachusetts strains were subjected to bioinformatics analysis.

Findings: On analysis of potential phosphorylation sites, the Ser542 and Ser563 sites were not present in Massachusetts strains, while QX-like isolates did not have the Ser534 site. Massachusetts and QX-like strains showed different cleavage site motifs. The N-glycosylation sites ASN-XAA-SER/THR-55, 147, 200 and 545 were additionally present in QX-like strains. The leucine-rich repeat regions in Massachusetts strains consisted of stretches of 63 to 69 amino acids, while in the QX-like strains they contained 59 amino acids in length. An additional palmitoylation site was observed in CK/SWE/082066/2010 a QX-like strain. Primary structure data showed difference in the physical properties and hydrophobic nature of both genotypes. The comparison of secondary structures revealed no new structural domains in the genotypic variants. The phylogenetic analyses based on avian and mammalian coronaviruses showed the analysed IBV as closely related to turkey coronaviruses and distantly related to thrush and munia coronaviruses.
\end{abstract}

Conclusion: The study demonstrated that spike glycoprotein of the Massachusetts and the QX-like variants of IBV are molecularly distinct and that this may reflect in differences in the behavior of these viruses in vivo.

Keywords: Infectious bronchitis virus, Spike glycoprotein, Bioinformatics, Coronavirus, Evolution

\section{Background}

Infectious bronchitis virus (IBV) causes avian infectious bronchitis, a highly contagious disease that affects poultry and produces severe economic losses worldwide. IBV belongs to the order of Nidovirales, family Coronaviridae and to genus of Gamma-coronavirus group 3 [1]. The genome is positive-sense single stranded RNA of about $27.6 \mathrm{~kb}$ and contains $5^{\prime}$ and $3^{\prime}$ untranslated regions [2-4].

The Massachusetts strain was initially isolated in 1940 in USA and clinically characterized as causing respiratory signs and decrease in egg production. It is widely

\footnotetext{
* Correspondence: Shahid.hussein.abro@sva.se

${ }^{1}$ Department of Biomedical Sciences and Veterinary Public Health, Section of Virology, The Swedish University of Agricultural Sciences, Ulls Väg 2B, SE-751 89, Uppsala, Sweden

${ }^{2}$ Department of Virology, Immunobiology and Parasitology, The National Veterinary Institute, Ulls Väg 2B, SE-751 89, Uppsala, Sweden
}

distributed and predominant in many countries around the world [5]. The Massachusetts strain can infect different organs and some of the isolates could be recovered from gastrointestinal tract especially from the cecal tonsils $[6,7]$. First IBV QX infections characterized by swelling of stomach in chicken flocks were reported in Qingdao China in 1996 [8]. Following the years the IBV QX viral infections was associated to either proventriculitis or renal infections in IBV vaccinated flocks in China $[9,10]$. The decreases in egg production and false layers in mature hens in chicken flocks were also reported with QX infections $[10,11]$. Later on Chinese QX of IBV was isolated from a backyard flock in Russia where the prevalence of Chinese QX-like genotype was common [12,13]. Subsequently there have been increasing reports of QX-like cases in Europe, where the involved virus bearded sequence similarities to QX-like viruses, such as the cases

\section{Biomed Central}


in Belgium, Denmark, France, Hungry, Germany, The Netherlands, Poland, Russia, Slovenia, Spain, Sweden, and UK [7,14-19]. These IBV viruses were termed as European QX-like viruses symptoms associated with bad egg quality, false layers in mature hens [2].

The spike glycoprotein of the virus is translated as a pre-cursor protein $\left(\mathrm{S}_{\mathrm{O}}\right)$ that is later cleaved into the $\mathrm{N}$-terminal S1 and C-terminal S2 glycopolypeptides. The spike gene is highly variable, especially the S1 part, due to insertions, deletions, substitutions and recombination events $[14,20,21]$. The S1 part of the spike glycoprotein contains serotype specific virus neutralizing epitopes and is responsible for the hemagglutinating activity and for infectivity [22]. Due to this variability in nucleotide sequences, the cross protection between serotypes is low. Changes as little as 5\% in the S1 sub-unit have been able to alter the protection ability of a vaccine [23]. The spike glycoprotein cleavage site motif has been described in bovine coronavirus, turkey coronavirus and human coronavirus, however, it is not found in all coronaviruses [24]. The cleavage recognition site in the spike glycoprotein of IBV consists of five basic amino acids, which is cleaved by host cell serine proteases [25]. Serine proteases are hydrolases that cleave peptide bonds $[26,27]$. The cleavage recognition site sequence is not involved in pathogenicity because attenuated and pathogenic strains (same virus) possess identical cleavage recognition site sequences [26]. The spike glycoprotein of IBV is involved in induction of protective immunity, neutralization and attachment to the host cell $[28,29]$. It contains crucial virus neutralizing epitopes and serotypic specific sequences that are involved in, induction of protective immunity, tissue tropism and attachment into host cells [22,25,30-32].

Palmitoylation is essential for the screening, localization and trafficking at sub-cellular level, protein-protein interactions, and to pre-determine functional properties of proteins $[33,34]$. N-glycosylation properties of the glycoprotein were shown to be involved in changes of virulence and cellular tropism in lactate dehydrogenase-elevating virus [35]. Protein phosphorylation has key role in regulation of physiological functions in the cells of prokaryotes and eukaryotes [36]. Leucine-rich repeat (LRR) is a structural motif of the protein like a alpha/beta horseshoe fold which is relevant for protein-protein interactions $[37,38]$. In this study, palmitoylation, leucine-rich repeat and $\mathrm{N}$ glycosylation characteristics of IBV Massachusetts and QX-like strains were evaluated using bioinformatics tools in order to determine the extent of difference in structural and functional features between the strains.

The objective of the present study was to analyze the molecular characteristics of selected isolates belonging to classical (Massachusetts) and emerging (QX-like) genotypes of IBV to indentify differences in potential functional motifs of the spike glycoprotein, predicted by bioinformatics analysis. In addition an evolution analysis with regards to avian and mammalian coronavirus was performed.

\section{Results}

\section{Prediction of $\mathrm{N}$-glycosylation}

The loss or acquisitions of $\mathrm{N}$-glycosylation sites in the spike protein were predicted. Thirty $\mathrm{N}$-glycosylation sites were found in the Massachusetts strains, while $35 \mathrm{~N}$-glycosylation sites were present in the QX-like strains. The N-glycosylation sites ASN-XAA-SER/THR$55,147,200$ and 545 were additionally present in spike gene of QX-like strains. The results revealed that most of the $\mathrm{N}$-glycosylation sites were conserved within genotype in the analyzed strains, except in strain CK/SWE/ 082066/10 that had lost ASN-XAA-SER/THR-533.

\section{Analysis of potential phosphorylation sites}

The analyses revealed that there were different in number and location of potential phosphorlated peptides in the spike glycoprotein. In Massachusetts isolates phosphorylation sites at position Ser54, Ser79, Ser312, Ser404, Ser534, Ser618, Ser685, Ser908 and Ser1061 were found to be conserved. While two isolates CK/SWE/242/95 and CK/SWE/748/95 that did not contain phosphorylation sites at position Ser542 and Ser563. In contrast, they contained additional potential phosphorylation sites at Ser177 and Ser878. QX-like strains did not contain a potential phosphorylation site at position Ser534 and acquired a new potential phosphorylation site at position Ser513.

\section{Proteolytic cleavage sites in the spike glycoprotein}

The cleavage site motifs of analyzed strains are presented in Table 1. Massachusetts and QX-like strains showed a different cleavage site motif. From the analyzed strains of both genotypes, six strains have shown the cleavage site at amino acid position 537 arginine, while two strains CK/SWE/242/95 and CK/SWE/748/95 presented cleavage site at histidine.

\section{Determination of leucine-rich repeat regions}

Leucine-rich repeat (LRR) regions were observed in the spike glycoprotein consisting of 59 to 69 amino acids in length. In isolate CK/SWE/748/95 two LRR regions were found, starting at position at 771 (ATQLQARNNAL) and 1147 (LEKLSILKTYI), respectively. The LRR regions in Massachusetts strains consisted of stretches of 63 to 69 amino acids, while in the QX-like strains they contained 59 amino acids in length.

\section{Prediction of palmitoylation sites}

The isolates CK/SWE/748/95, CK/SWE/1096/97 and CK/SWE/062545/09 contained 10 palmitoylation sites in the spike glycoprotein of the virus. The isolate CK/ 
Table 1 Cleavge site motif in Swedish IBV strains

\begin{tabular}{|c|c|c|}
\hline Strian & Type & $\begin{array}{l}\text { Cleavage site sequence } \\
\text { motif }\end{array}$ \\
\hline CK/SWE/242/95 & Massachusetts & ${ }^{535}$ Aln-Gly-His-Ser-Ile $e^{539}$ \\
\hline CK/SWE/748/95 & Massachusetts & ${ }^{535}$ Aln-Gly-His-Ser-Ile ${ }^{539}$ \\
\hline CK/SWE/423/97 & Massachusetts & ${ }^{535}$ Leu-Arg-Arg-Ser-Ile ${ }^{539}$ \\
\hline CK/SWE/1096/97 & Massachusetts & ${ }^{535}$ Leu-Arg-Arg-Ser-II e $^{539}$ \\
\hline CK/SWE/062545/09 & QX-like & 535 Ser-His-Arg-Thr-Arg ${ }^{539}$ \\
\hline CK/SWE/062561/09 & QX-like & 535 Ser-His-Arg-Thr-Arg 539 \\
\hline CK/SWE/079692/10 & QX-like & 535 Ser-Gln-Arg-Arg-Arg ${ }^{539}$ \\
\hline CK/SWE/082066/10 & QX-like & 535 Ser-Gln-Arg-Arg-Arg ${ }^{539}$ \\
\hline
\end{tabular}

Cleavage site at amino acid position $537=$

Amino acid abbreviations: Aln = alanine, Gly = glycine, His = histidine, Ser = serine.

Ile = Isoleucine, $\mathrm{Thr}=$ threonine, $\mathrm{Arg}=$ arginine, $\mathrm{Gln}=$ glutamine .

SWE/082066/2010 contained additional palmitoylation site 1130 (CGGCFGI) in comparison to the all other analyzed isolates.

\section{Primary structure of the spike glycoprotein}

The data regarding the primary structures are presented in (Additional file 1: Table S1). The strains of Massachusetts group were found to have differences of approximately $0.3-1.2 \mathrm{KDa}$ in their molecular weights, while QX-like strains possessed similar molecular weight. The isoelectric points (pI) 5.63-6.72 of the Massachusetts strains were comparatively higher than pI 5.73 of QXlike strains. There were 82-87 positively charged residues (Arg + Lys) in the QX-like strains, 2-4 residues more than Massachusetts strains. The computed instability index and aliphatic index (AI) showed variable values (83.79-85.91) in all analyzed strains. The grand hydropathicity (GRAVY) was found to have negative values in all strains. The primary structure data showed difference in the hydrophobic nature of both genotypes. The primary structures of the spike glycoprotein were found to be relatively variable in the strains.

\section{Prediction of secondary structures of spike glycoproteins}

The data regarding the secondary structures are presented in (Additional file 2: Table S2). All the analyzed isolates contained 18 to 19 alpha helices, $47-58$ beta sheets and 63-73 residual coils. In the case of alpha helices and beta sheets, there was additionally one alpha helix and 11 beta strands in Massachusetts strains than in QX-like strains.

\section{Phylogenetic analysis}

The phylogenetic analysis of the complete spike gene based on avian coronaviruses revealed the sequences of the analysed strains segregated into three main groups (Figure 1). Group I was composed of IBV sequences that clustered together with those of Massachusetts,
Arkansas and QX-like genotypes, as previously described by Abro et al. (2012) [14]. The definition of those genotypes is supported by high bootstrap values of $100 \%$. Group II consisted of turkey coronaviruses branching closely to the IBV. Group III consisted of sequences of munia and thrush coronaviruses, branching into two clusters: one comprising munia coronaviruses and the other thrush coronaviruses. The high bootstrap values (100\%) indicate a true distance between these clusters and that they are likely species-specific.

The phylogenetic analysis based on the spike glycoprotein of avian and mammalian coronaviruses strains has shown as the following discrimination (Figure 2): a) Sequences of IBV and turkey coronaviruses making the majority of avian coronaviruses. The sequences of Beluga whale coronaviruses and one bat-coronavirus HKU2 were distantly related to this branch of avian sequences, altogather composing the gama-coronaviruses. b) A set of sequences comprising separate clusters of avian, bat, human and feline coronaviruses, thus including both avian and mammalian coronaviruses. c) A set of strictly mammalian coronaviruses, branching into the SARS, human coronavirus HKU1, bat coronaviruses and a cluster majorly of animal coronaviruses comprising murine, equine, porcine and bovine coronaviruses. The sequence of human coronavirus OC43 was found in this cluster, curiously identical to a coronavirus identified in pigs and closely related to bovine coronaviruses. Porcine hemagglutinating encephalomyelitis virus occupied a distinct place between the human and equine coronaviruses clusters.

\section{Discussion}

A genetic analysis of the complete spike glycoprotein of selected isolates of Massachustes and QX-like strains was carried out in order to predict molecular features by application of molecular and In silico technologies.

In the isolate CK/SWE/082066/10, amino acid phenylalanine substituted asparagine resulting in the loss of a potential $\mathrm{N}$-glycosylation site at position 533 . The five additional $\mathrm{N}$-glycosylation sites found in QX strains may influence cellular tropism. The variation in $\mathrm{N}$-glycosylation sites may affect survival and transnsmission of the virus. The small changes can lead to disturbance in folding and conformation of the molecule. The variations in Nglycosylation sites may affect the interaction with receptors and render a virus more susceptible to host innate immune system and lower recognition by antibody, hence affecting the virus replication and infectivity [39-42]. In a virus belonging to the Coronaviridae, lactate dehydrogenase elevating virus (LDEV), the loss or acquisition of $\mathrm{N}$ glycosylation sites in the protein has been reported to determine changes of virulence and cellular tropism [35].

The presence of serine, threonine and tyrosine residues, with the right context for potential phosphorylation was 


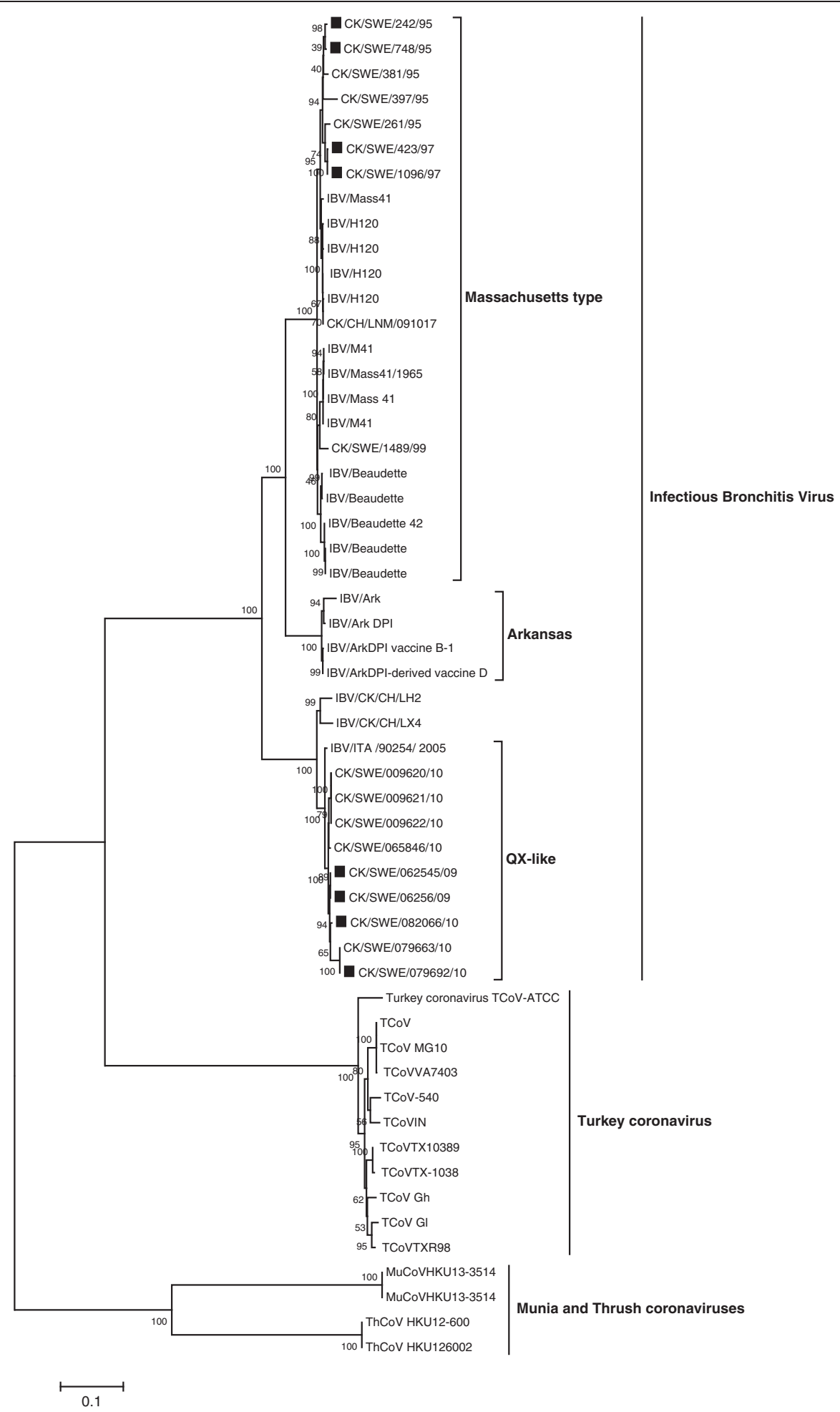

Figure 1 Phylogenetic analysis based on complete spike gene of avian coronaviruses showing the relationship between IBV and avian coronaviruses. The isolates analysed in this study are indicated by square. 


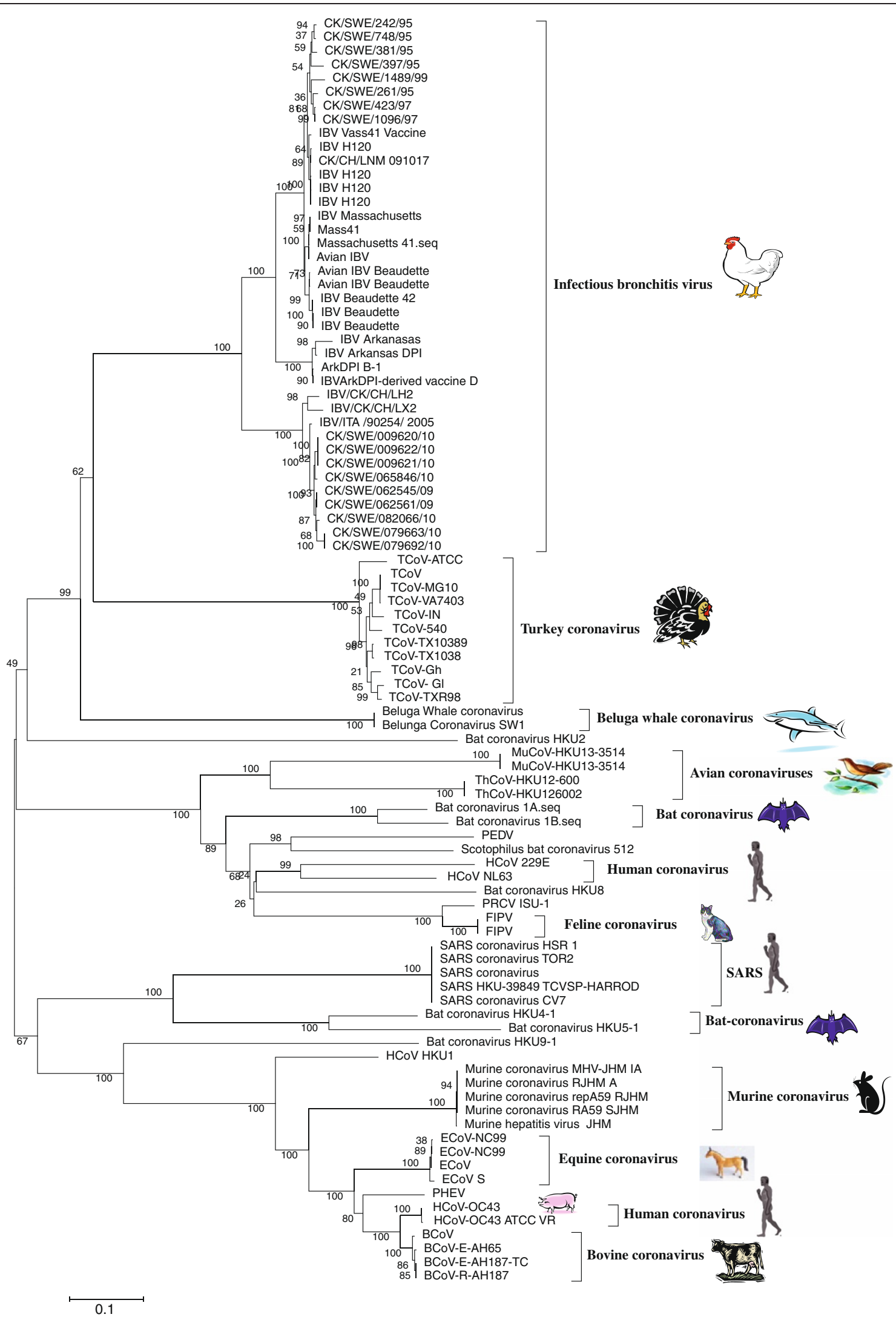

Figure 2 (See legend on next page.) 
(See figure on previous page.)

Figure 2 Phylogenetic analysis based on complete spike gene of avian and mammalian coronaviruses showing the relationship between coronaviruses in different host species.

investigated in the spike glycoprotein. The results have shown that the spike glycoprotein of IBV genotypes contained serine and thereonine peptides with potential for phosphorylation. The substitution of a serine by amino acid alanine at positions 563 caused loss of a potential phosphorylated peptide in strains CK/SWE/242/95 and CK/SWE/748/95. Wilbur et al. (1986) reported that $\mathrm{N}$ protein is the only structural protein that contained phosphorylation activity in coronaviruses [43]. In this context we have observed potential phosphorylated peptides in the spike glycoprotein of IBV; however, this seems to be of no consequence for phosphorylation, since this property has not been identified in the spike which is well established as a glycoprotein.

The difference in cleavage site motifs of the spike glycoprotein of both genotypes, seem to indicate a correlation with geographical distribution of strains. It has been reported that serotypically and genotypically different IBV contain distinct cleavage site in the spike protein. However, the cleavage site sequence did not correlate with pathogenicity by comparing cleavage recognition sites in pathogenic and attenuated strains of IBV [26]. The cleavage site motifs determined in Massachusetts and QX-like strains in present study are different from previously reported by Jackwood et al. (2001) [26]. The replacement of arginine with histidine at amino acid position 537 in CK/SWE/748/95 and CK/SWE/748/95 may have influence antibody binding epitope. However, the functional meaning of this difference needs to be evaluated in proper biological assays. It has been reported that an IBV monoclonal antibody neutralization-resistant mutant (NR 18) had shown substitution of amino acid isoluecine for arginine in cleavage site motif which prevented cleavage and alter the conformation dependent monoclonal antibody binding epitope [26]. In orthomyxoviruses and paramyxoviruses more basic residues around the cleavage recognition site of the envelope glycoproteins enhance the cleavability by ubiquitous host cell proteases, a characteristic which is associated with host cell range and increased virulence $[44,45]$. However, the relevance of cleavage site to virulence was not observed in case of IBV spike glycoprotein [26].

The data regarding leucine-rich repeat regions of isolate CK/SWE/748/95 demonstrated that two LRR regions may result in strong folding capacity in the spike glycoprotein. It has been reported that leucine-rich repeat (LRR) is a structural motif of protein like a alpha/ beta horseshoe fold and is responsible for proteinprotein interactions $[37,38]$.
An additional palmitoylation site was found only in isolate CK/SWE/082066/10, indicating that it is strain specific. However, experimental studies are required to identify the effect of additional palmitoylation in the virus biology. In influenza virus, palmitoylation of the cytoplasmic domain of the hemagglutinin has been shown to increase its association with lipid mass [46]. The deletion of palmitoylation sites in the hemagglutinin domain reduces hemagglutinin incorporation into the virion, thereby affecting the cellular trafficking [47]. It has been reported that removal of palmitoylation sites in HIV-1 virus effected in the formation of virus with low levels of glycoproteins incorporation and reduced infectivity [48]. Shen et al. (2009) reported attenuation of virus replication occurring due to mutations in the palmitoylation site in the non-structural protein nsp1 of Semliki Forest virus [49].

The predicted primary structures of the spike glycoprotein of both genotypic variants have shown a variable trend in physical properties such as isoelectric point, molecular weights and grand hydropathicity index. Grand average of hydropathicity index results suggested a hydrophobic nature of the spike glycoprotein in all variants. Cavanagh et al. (1986) reported that S2 subunit in N-terminal side of the membrane spanning hydrophobic domain of spike glycoprotein of IBV is susceptible to hydrolysis by many proteases [32].

The secondary structures prediction revealed that structures of the spike glycoprotein were found variable in both genotypic variants. It was also observed that there were no new structural domains and that no evolution has occurred in the structure of both genotypic variants. However, secondary structural variation in beta strands and residual coils have been observed between both genotypic strains.

A number of phylogenetic studies performed on the spike gene were mostly based on the partial sequences of S1 and N gene. Phylogenetic analyses based on the complete spike glycoprotein of avian coronaviruses demonstrated that IBV strains showed higher relatedness to turkey coronaviruses in comparison to other avian coronaviruses (Figure 1). This could be due to cohabitation of their host species. The appearance of a bat coronavirus branch close to these gammacoronaviruses suggests a possible common origin during earlier evolution of these viruses. The diversity of these viruses could have arisen from strong selective pressure resulting from mutations and recombinations that has been shown to occur in spike gene $[14,50,51]$. 
Phylogenetic analysis based on spike glycoprotein of avian coronaviruses and mammalian coronaviruses had revealed interesting trends. The mammalian beluga whale coronaviruses branched closer to the avian coronaviruses and two avian thrush and munia coronaviruses were related to the mammalian coronaviruses suggesting interspecies transmission. Furthermore, findings of the present study suggest that genetic diversity and molecular variation in sequences of spike glycoprotein of viruses made feasible the adaptation to new host species. Previously it has been reported that the RNA-dependant RNA polymerase gene and the whole genome of the beluga whale coronavirus was distantly related to IBV $[52,53]$. Also a shift of tissue tropism in the virus has been reported $[54,55]$ resulting in infection of a wide range of avian host species especially those reared close to domestic fowl. For example, IBV cases were found in guinea fowl (Numida meleagris), Chinese peafowl (Pavo), teal (Anas) and partridge (Alectoris) [56].

The higher diversity in the avian, humans and batcoronaviruses are due to continuous mutation, which may determine differences in tissue tropism. Previously it has been reported that diversity of coronaviruses due to a) infidelity of RNA-dependant RNA polymerase which lead to incorporation of nucleotide errors during replication $[34,57]$; b) random template switching during RNA replication (copy choice mechanism) high rate of homologous RNA recombination events $[4,58]$; c) extra plasticity nature in adjusting and modifying genes [59]. These factors were responsible for the generation and diversification of variants and adaption to new hosts and ecological niches in the coronaviruses $[53,59]$.

\section{Conclusions}

In silico predictions confirm previous data on phylogenetic analysis, showing that the spike glycoprotein of the Massachusetts and QX genotypes are molecularly different. Since the spike glycoprotein has important role in cell attachment, receptor recognition, the genetic diversity seen in this protein of IBV, avian, human, bat, and other animal coronaviruses may bear relation with host specificity. The identification of these characteristics will be foundation for the better understanding of epidemics, molecular mechanisms of infections, evolution and basis for development of effective vaccines. Bioinformatics approach is easy to perform, cheap and suitable to obtain predictions about functional motifs in a genome. However, the predicted findings require validation through proper laboratory experimentation.

\section{Methods}

\section{Sequence data set}

The sequence data set generated as previously described by Abro et al. (2012) [14] was used for the analysis (Additional file 3: Table S3).

\section{Bioinformatics analysis}

$\mathrm{N}$-glycosylation sites were predicted by services available on http://www.cbs.dtu.dk/services/NetNGlyc. The potential phosphorylation sites were determined by using website http://www.cbs.dtu.dk/services/NetPhos. Leucine-rich repeat regions were determined by LRRfinder available at http://www.lrrfinder.com/result.php. Antigenic determinants were predicted with the maximum score with the high confidence for positive determinant motif in the amino acid sequence with the help of server http:// mobyle.pasteur.fr. The primary structures of the spike glycoprotein were predicted by http://expasy.org/tools. Palmitoylation sites were predicted with the medium threshold frequency by using services at http://csspalm. biocuckoo.org/prediction.php. The secondary structures (alpha helices, beta strands and random coils) of the protein were predicted by using bioinformatics tools available on website http://npsa-pbil.ibcp.fr. The method of GOR4 http://npsa-pbil.ibcp.fr/cgi-bin/npsa_automat.pl?page=npsa_gor4.html was used to identify the alpha helices, beta strands and coil residues. At least minimum three or more turns were taken in account for one helix, strand or coil in the structure of spike glycoprotein.

\section{Phylogenetic analysis}

The comprehensive phylogenetic study was carried out based on the complete spike gene of avian and mammalian coronaviruses available in GenBank. The sequences included IBV Massachusetts type, M41, H120, Baudette, Arkansas, QX like strains and other sequences of Turkey coronavirus (TCoV), thrush coronavirus (ThCoV), munia coronavirus (MuCoV), human coronavirus ( $\mathrm{HCoV})$, SARS (Severe acute respiratory syndrome) coronavirus, bovine coronavirus $(\mathrm{BCoV})$, equine coronavirus $(\mathrm{ECoV})$, mouse hepatitis virus (MHV), murine coronavirus (MurCoV), feline coronavirus (FCoV), porcine epidemic diarrhea virus (PEDV), porcine respiratory coronavirus (PRCV), porcine hamagglutinating encephalalomylitis virus (PHEV), bat coronavirus and beluga whale coronavirus sequences (Additional file 3: Table S3; Additional file 4: Table S4). Multiple sequence alignment of complete spike gene was performed with CLUSTAL W [60]. All the gaps in the sequences created by insertions were deleted by using software Mega4 version 4 [61]. Phylogenetic trees were constructed by the Neighbour-joining method with the nucleotide substitution model of Kimura-2 parameter model. The tree reliability/robuststness of the hypothesis were evaluated by bootstrap of 1000 replicates. The data set was kept similar for the analysis. The Bayesian analyses were performed by using the software MrBayes 3.1 [62]. The model was set for the substitution rates lset nst $=6$, rates of variation were performed by gamma distribution (rates $=$ invgamma $)$ posterior probability distribution ensured and 2000000 generation were run and standard 
deviation of split frequencies at .01. The output of the substitution model parameters were summarized with sump burnin $=250$. The tree topology was prepared in the FigTree_v1.3.1. The trees were generated with various methods and the consensus tree was taken into account in this study.

\section{Additional files}

\section{Additional file 1: Table S1. Predicted primary structures of spike} glycoprotein.

Additional file 2: Table S2. Predicted secondary structures of spike glycoprotein.

Additional file 3: Table S3. List of selected Swedish IBV strains and reference strains of avian coronaviruses of which sequences were downloaded from GenBank for the phylogenetic analysis in this study. The IBV strains analyzed in this study are indicated by star*

Additional file 4: Table S4. List of reference strains of mammalian coronavirus sequences were downloaded from GenBank for the phylogenetic analysis in this study.

\section{Competing interests}

The authors have declared that they have no competing interests.

\section{Authors' contributions}

Study concepts and design: SHA, CB Performance of experiments: SHA, KU Analysis of the data: SHA, CB Writing of the manuscript: SHA, KU, SB, CB. The authors have read and approved the final manuscript.

\section{Acknowledgements}

This study was funded by Grant 70031/2009 of The National Veterinary Institute (SVA) Research Fund.

Received: 1 March 2012 Accepted: 7 September 2012

Published: 19 September 2012

\section{References}

1. Gonzalez JM, Gomez-Puertas P, Cavanagh D, Gorbalenya AE, Enjuanes L: A comparative sequence analysis to revise the current taxonomy of the family Coronaviridae. Arch Virol 2003, 148:2207-2235.

2. Abro SH, Renstrom LH, Ullman K, Belak S, Baule C: (2012) Characterization and analysis of the full-length genome of a strain of the European QX-like genotype of infectious bronchitis virus. Arch Virol 2012 , 157:1211-1215.

3. Cavanagh D: Coronavirus avian infectious bronchitis virus. Vet Res 2007, 38:281-297

4. Pasternak AO, Spaan WJ, Snijder EJ: Nidovirus transcription: how to make sense. ..?. J Gen Virol 2006, 87:1403-1421.

5. Fabricant J: The early history of infectious bronchitis. Avian Dis 1998 , 42:648-650.

6. Lucio B, Fabricant J: Tissue tropism of three cloacal isolates and Massachusetts strain of infectious bronchitis virus. Avian Dis 1990 34:865-870.

7. Benyeda Z, Mato T, Suveges T, Szabo E, Kardi V, Abonyi-Toth Z, Rusvai M, Palya V: Comparison of the pathogenicity of QX-like, M41 and 793/B infectious bronchitis strains from different pathological conditions. Avian Pathol 2009, 38:449-456.

8. YuDong W, YongLin W, ZiChun Z, GenChe F, YiHai J, XiangE L: Isolation and identification of glandular stomach type IBV (QX IBV) in chickens. Chinese J Anim Quarantine 1998, 15:419-422

9. $\quad Y u$ L, Wang Z, Jiang $Y$, Low S, Kwang J: Molecular epidemiology of infectious bronchitis virus isolates from China and Southeast Asia. Avian Dis 2001, 45:201-209.

10. Liu S, Kong X: (2004) A new genotype of nephropathogenic infectious bronchitis virus circulating in vaccinated and non-vaccinated flocks in China. Avian pathol 2004, 33:321-327.
11. Lee HJ, Youn HN, Kwon JS, Lee YJ, Kim JH, Lee JB, Park SY, Choi IS, Song CS: Characterization of a novel live attenuated infectious bronchitis virus vaccine candidate derived from a Korean nephropathogenic strain. Vaccine 2010, 28:2887-2894.

12. Bochkov YA, Batchenko GV, Shcherbakova LO, Borisov AV, Drygin W Molecular epizootiology of avian infectious bronchitis in Russia. Avian pathol 2006, 35:379-393.

13. Gough RE, Cox WJ, de BWD, Worthington KJ, Jones RC: Chinese QX strain of infectious bronchitis virus isolated in the UK. Vet rec 2008, 162:99-100.

14. Abro SH, Renstrom LH, Ullman K, Isaksson M, Zohari S, Jansson DS, Belak S, Baule C: Emergence of novel strains of avian infectious bronchitis virus in Sweden. Vet Microbiol 2012, 155:237-246.

15. Domanska-Blicharz K, Minta Z, Smietanka K, Porwan T: New variant of IBV in Poland. Vet Rec 2006, 158:808.

16. Krapez U, Slavec B, Rojs OZ: Circulation of infectious bronchitis virus strains from Italy 02 and QX genotypes in Slovenia between 2007 and 2009. Avian Dis 2011, 55:155-161.

17. Valastro V, Monne I, Fasolato M, Cecchettin K, Parker D, Terregino C, Cattoli G: (2010) QX-type infectious bronchitis virus in commercial flocks in the UK. Vet Rec 2010, 167:865-866.

18. Worthington KJ, Jones RC: New genotype of infectious bronchitis virus in chickens in Scotland. Vet Rec 2006, 159:291-292.

19. Worthington KJ, Currie RJ, Jones RC: A reverse transcriptase-polymerase chain reaction survey of infectious bronchitis virus genotypes in Western Europe from 2002 to 2006. Avian pathol 2008, 37:247-257.

20. Adzhar A, Gough RE, Haydon D, Shaw K, Britton P, Cavanagh D: Molecular analysis of the 793/B serotype of infectious bronchitis virus in Great Britain. Avian pathol 1997, 26:625-640.

21. Farsang A, Ros C, Renstrom LH, Baule C, Soos T, Belak S: Molecular epizootiology of infectious bronchitis virus in Sweden indicating the involvement of a vaccine strain. Avian pathol 2002, 31:229-236.

22. Cavanagh D, Davis PJ: Coronavirus IBV: removal of spike glycopolypeptide S1 by urea abolishes infectivity and haemagglutination but not attachment to cells. J Gen Virol 1986, 67(Pt 7):1443-1448.

23. Casais R, Dove $B$, Cavanagh D, Britton P: Recombinant avian infectious bronchitis virus expressing a heterologous spike gene demonstrates that the spike protein is a determinant of cell tropism. J Virol 2003, 77:9084-9089.

24. Holmes KV: (1990) Coronaviridae and their repli-cation. In Virology, 2nd edition. Edited by Fields BN, Knipe DM. New York: Raven Press, Ltd; 1990:841-856

25. Cavanagh D, Davis PJ, Pappin DJ, Binns MM, Boursnell ME, Brown TD: Coronavirus IBV: partial amino terminal sequencing of spike polypeptide S2 identifies the sequence Arg-Arg-Phe-Arg-Arg at the cleavage site of the spike precursor propolypeptide of IBV strains Beaudette and M41. Virus Res 1986, 4:133-143.

26. Jackwood MW, Hilt DA, Callison SA, Lee CW, Plaza H, Wade E: Spike glycoprotein cleavage recognition site analysis of infectious bronchitis virus. Avian Dis 2001, 45:366-372.

27. Voet D, Voet JG: Biochemistry. New York: John Wiley and Sons, Inc; 1990:373-382

28. Ignjatovic J, Galli L: The S1 glycoprotein but not the N or M proteins of avian infectious bronchitis virus induces protection in vaccinated chickens. Arch Virol 1994, 138:117-134.

29. Johnson MA, Pooley C, Ignjatovic J, Tyack SG: A recombinant fowl adenovirus expressing the $\mathrm{S} 1$ gene of infectious bronchitis virus protects against challenge with infectious bronchitis virus. Vaccine 2003, 21:2730-2736

30. Karaca K, Naqi S, Gelb J Jr: Production and characterization of monoclonal antibodies to three infectious bronchitis virus serotypes. Avian Dis 1992, 36:903-915

31. Koch G, Hartog L, Kant A, van Roozelaar DJ: Antigenic domains on the peplomer protein of avian infectious bronchitis virus: correlation with biological functions. J Gen Virol 1990, 71(Pt 9):1929-1935.

32. Cavanagh D, Davis PJ, Pappin DJ: Coronavirus IBV glycopolypeptides: locational studies using proteases and saponin, a membrane permeabilizer. Virus Res 1986, 4:145-156.

33. Dietrich $L E$, Ungermann $C$ : On the mechanism of protein palmitoylation. EMBO Rep 2004, 5:1053-1057.

34. Duffy S, Shackelton LA, Holmes EC: Rates of evolutionary change in viruses: patterns and determinants. Nat Rev Genet 2008, 9:267-276. 
35. Li K, Schuler T, Chen Z, Glass GE, Childs JE, Plagemann PG: Isolation of lactate dehydrogenase-elevating viruses from wild house mice and their biological and molecular characterization. Virus Res 2000, 67:153-162.

36. Ingrell CR, Miller ML, Jensen ON, Blom N: NetPhosYeast: prediction of protein phosphorylation sites in yeast.Bioinformatics 2007 23:895-897.

37. Gay NJ, Packman LC, Weldon MA, Barna JC: A leucine-rich repeat peptide derived from the Drosophila Toll receptor forms extended filaments with a beta-sheet structure. FEBS Lett 1991, 291:87-91.

38. Kobe B, Deisenhofer J: The leucine-rich repeat: a versatile binding motif. Trends Biochem Sci 1994, 19:415-421.

39. Land A, Braakman I: Folding of the human immunodeficiency virus type 1 envelope glycoprotein in the endoplasmic reticulum. Biochimie 2001, 83:783-790

40. Slater-Handshy T, Droll DA, Fan X, Di Bisceglie AM, Chambers TJ: HCV E2 glycoprotein: mutagenesis of $\mathrm{N}$-linked glycosylation sites and its effects on E2 expression and processing. Virology 2004, 319:36-48.

41. Meunier JC, Fournillier A, Choukhi A, Cahour A, Cocquerel L, Dubuisson J, Wychowski C: Analysis of the glycosylation sites of hepatitis C virus (HCV) glycoprotein E1 and the influence of E1 glycans on the formation of the HCV glycoprotein complex. J Gen Virol 1999, 80(Pt 4):887-896.

42. Vigerust DJ, Shepherd VL: Virus glycosylation: role in virulence and immune interactions. Trends Microbiol 2007, 15:211-218.

43. Wilbur SM, Nelson GW, Lai MM, McMillan M, Stohlman SA: Phosphorylation of the mouse hepatitis virus nucleocapsid protein. Biochem Biophys Res Commun 1986, 141:7-12.

44. Glickman RL, Syddall RJ, lorio RM, Sheehan JP, Bratt MA: Quantitative basic residue requirements in the cleavage-activation site of the fusion glycoprotein as a determinant of virulence for Newcastle disease virus. J Virol 1988, 62:354-356

45. Webster RG, Kawaoka Y, Bean WJ Jr: Molecular changes in A/Chicken/ Pennsylvania/83 (H5N2) influenza virus associated with acquisition of virulence. Virology 1986, 149:165-173.

46. Melkonian KA, Ostermeyer AG, Chen JZ, Roth MG, Brown DA: Role of lipid modifications in targeting proteins to detergent-resistant membrane rafts. many raft proteins are acylated, while few are prenylated. J Biol Chem 1999, 274:3910-3917.

47. Zhang J, Pekosz A, Lamb RA: Influenza virus assembly and lipid raft microdomains: a role for the cytoplasmic tails of the spike glycoproteins. J Virol 2000, 74:4634-4644.

48. Rousso I, Mixon MB, Chen BK, Kim PS: Palmitoylation of the HIV-1 envelope glycoprotein is critical for viral infectivity. Proc Natl Acad Sci USA 2000, 97:13523-13525.

49. Shen C, Guo Y, Cheng A, Wang M, Zhou Y, Lin D, Xin H, Zhang N: Characterization of subcellular localization of duck enteritis virus UL51 protein. Virol J 2009, 6:92.

50. Lim TH, Lee HJ, Lee DH, Lee YN, Park JK, Youn HN, Kim MS, Lee JB, Park SY, Choi IS, Song CS: An emerging recombinant cluster of nephropathogenic strains of avian infectious bronchitis virus in Korea. Infect Genet Evol 2011, 11:678-685.

51. Gelb J Jr, Weisman Y, Ladman BS, Meir R: S1 gene characteristics and efficacy of vaccination against infectious bronchitis virus field isolates from the United States and Israel (1996 to 2000). Avian pathol 2005, 34:194-203.

52. Mihindukulasuriya KA, Wu G, St Leger J, Nordhausen RW, Wang D: Identification of a novel coronavirus from a beluga whale by using a panviral microarray. J virol 2008, 82:5084-5088.

53. Woo PC, Lau SK, Huang Y, Yuen KY: Coronavirus diversity, phylogeny and interspecies jumping. Exp Biol Med 2009, 234:1117-1127.

54. Liu SW, Zhang QX, Chen JD, Han ZX, Liu X, Feng L, Shao YH, Rong JG, Kong $X G$, Tong GZ: Genetic diversity of avian infectious bronchitis coronavirus strains isolated in China between 1995 and 2004. Arch Virol 2006, 151:1133-1148

55. Zhou JY, Zhang DY, Ye JX, Cheng LQ: Characterization of an avian infectious bronchitis virus isolated in China from chickens with nephritis. J Vet Med B Infect Dis Vet Public Health 2004, 51:147-152.

56. Cavanagh D: Coronaviruses in poultry and other birds. Avian pathol 2005, 34:439-448.

57. Jenkins GM, Rambaut A, Pybus OG, Holmes EC: Rates of molecular evolution in RNA viruses: a quantitative phylogenetic analysis. $J \mathrm{Mol}$ Evol 2002, 54:156-165.
58. Lai MM: RNA recombination in animal and plant viruses. Microbiol Rev 1992, 56:61-79.

59. Woo PC, Lau SK, Yuen KY: Infectious diseases emerging from Chinese wet-markets: zoonotic origins of severe respiratory viral infections. Curr Opin Infect Dis 2006, 19:401-407.

60. Thompson JD, Higgins DG, Gibson TJ: CLUSTAL W: improving the sensitivity of progressive multiple sequence alignment through sequence weighting, position-specific gap penalties and weight matrix choice. Nucleic Acids Res 1994, 22:4673-4680.

61. Tamura K, Dudley J, Nei M, Kumar S: MEGA4: Molecular Evolutionary Genetics Analysis (MEGA) software version 4.0. Mol Biol Evol 2007, 24:1596-1599

62. Ronquist F, Huelsenbeck JP: Mr Bayes 3: Bayesian phylogenetic inference under mixed models. Bioinformatics 2003, 19:1572-1574.

doi:10.1186/1743-422X-9-211

Cite this article as: Abro et al:: Bioinformatics and evolutionary insight on the spike glycoprotein gene of QX-like and Massachusetts strains of infectious bronchitis virus. Virology Journal 2012 9:211.

\section{Submit your next manuscript to BioMed Central and take full advantage of:}

- Convenient online submission

- Thorough peer review

- No space constraints or color figure charges

- Immediate publication on acceptance

- Inclusion in PubMed, CAS, Scopus and Google Scholar

- Research which is freely available for redistribution 